\title{
Clinical efficacy of argon plasma coagulation combined with cryotherapy for central airway stenosis caused by lung cancer
}

Zhiguo Wang, Wei Wang and Guocheng Wu*

\begin{abstract}
Background: This study aimed to study the clinical efficacy of argon plasma coagulation plus cryotherapy for central airway stenosis caused by lung cancer.

Methods: The clinical data of 177 patients with central airway stenosis caused by lung cancer received surgery from June, 2017 to July 2018 were retrospectively analyzed. According to different treatments, 43 patients received cryotherapy were included in the control group, while 134 patients received argon plasma coagulation plus cryotherapy were in the observation group. After propensity score matching, patients in the two groups were in a 1:1 ratio. The Karnofsky score, partial pressure of oxygen $\left(\mathrm{PaO}_{2}\right)$, arterial oxygen saturation $\left(\mathrm{SaO}_{2}\right)$, partial pressure of arterial carbon dioxide $\left(\mathrm{PaCO}_{2}\right)$ and adverse reactions in patients were analyzed one week before and after treatment. Besides, the survival rates of the two groups were compared.

Results: After propensity score matching, the baseline data were not significantly different between the two groups. The post-treatment Karnofsky scores in the two groups were significantly higher than those of before treatment, and the post-treatment score of the observation group was higher than that of the control group (all $P<0.05$ ). The posttreatment $\mathrm{PaO}_{2}$ and $\mathrm{SaO}_{2}$ in the observation group were both higher than those of the control group; while the $\mathrm{PaCO}_{2}$ in the observation group was significantly lower than that of the control group (all $P<0.05$ ). In the observation group, the levels of $\mathrm{PaO}_{2}$ and $\mathrm{SaO}_{2}$ were significantly higher, and the level of $\mathrm{PaCO}_{2}$ was significantly lower after treatment than those of before treatment (all $P<0.05$ ). The rates of completely effective and mild effective in the observation group were significantly higher than those in the control group (both $P<0.05$ ). The incidences of bleeding, arrhythmia and fever in the observation group were significantly lower than those in the control group (all $P<0.05$ ). The survival rate was significantly higher in the observation group (72.09\%) than in the control group (51.16\%).
\end{abstract}

Conclusions: Argon plasma coagulation combined with cryotherapy can significantly alleviate the central airway stenosis caused by lung cancer, reduce the incidence of adverse reactions, and improve prognosis in patients.

Keywords: Argon plasma coagulation, Cryotherapy, Central airway stenosis

\footnotetext{
* Correspondence: wuguocheng45x@163.com

Department of Respiratory and Critical Care Medicine, The PLA Navy Anqing Hospital, Anqing 246003, Anhui Province, China
}

(c) The Author(s). 2019 Open Access This article is distributed under the terms of the Creative Commons Attribution 4.0 International License (http://creativecommons.org/licenses/by/4.0/), which permits unrestricted use, distribution, and reproduction in any medium, provided you give appropriate credit to the original author(s) and the source, provide a link to the Creative Commons license, and indicate if changes were made. The Creative Commons Public Domain Dedication waiver (http://creativecommons.org/publicdomain/zero/1.0/) applies to the data made available in this article, unless otherwise stated. 


\section{Background}

Lung cancer is currently with a high clinical incidence, and most patients did not realize the cancer until advanced stage due to its atypical symptoms. At this stage, patients may suffer symptoms such as central airway stenosis, shortness of breath, hemoptysis, and cough [1]. Chemotherapy can not reduce the size of tumor tissues in the trachea in a short period of time, and may induce edema, further aggravating airway obstruction [2]. Traditional surgery can lead to large trauma on patients, so some patients cannot directly undergo surgery because of their poor physical condition [3]. Cryotherapy refers to the use of liquid gas (such as nitrogen or carbon dioxide) to freeze the lesion tissues, resulting in damage and necrosis in structure under low temperature, which makes lesions easy to remove [4]. The argon plasma coagulation performs non-contact thermocoagulation on the lesions by ionizing argon gas, thereby clearing the lesion tissues [5]. The dyspnea index refers the respiratory state of the patient, and higher level indicates worse respiratory state [6]. The Karnofsky score is a measure of overall health, and increase in the score indicates health improvement in the patient [7]. Study in 47 patients with tumor-induced central airway stenosis treated by argon plasma coagulation plus cryotherapy showed improved or disappeared symptoms such as dyspnea, cough, and hemoptysis, as well as significantly improved respiratory function in patients [8]. Nevertheless, cryotherapy can poorly clear major tumor tissues, and easily cause bleeding from the wound during operation. The argon plasma coagulation damages the lesion tissues through thermal effect, which may injure patient's tracheal mucosa in a certain degree [9]. In this study, argon plasma coagulation combined with cryotherapy were used to treat central airway stenosis caused by lung cancer, so as to analyze the effect of the combination on central airway stenosis.

\section{Materials and methods}

Subjects

Clinical data of 177 patients with central airway stenosis caused by lung cancer who underwent surgery from June

Table 1 Clinical data

\begin{tabular}{|c|c|c|c|c|}
\hline Group & Control group $(n=43)$ & Observation group $(n=134)$ & $t / x^{2}$ & $P$ \\
\hline Gender (male / female) & $26 / 17$ & $73 / 61$ & 0.668 & 0.491 \\
\hline Age (year) & $46.7 \pm 5.3$ & $45.2 \pm 4.8$ & 1.739 & 0.084 \\
\hline Weight (kg) & $57.37 \pm 6.72$ & $58.51 \pm 7.29$ & 0.909 & 0.365 \\
\hline $\mathrm{BMI}\left(\mathrm{kg} / \mathrm{m}^{2}\right)$ & $23.28 \pm 3.83$ & $21.36 \pm 4.32$ & 2.604 & 0.010 \\
\hline Nutritional status (n) & & & 1.801 & 0.072 \\
\hline Good & 16 & 63 & & \\
\hline Poor & 27 & 71 & & \\
\hline Airway obstruction (n) & & & 2.879 & 0.004 \\
\hline Mild & 14 & 31 & & \\
\hline Severe & 29 & 103 & & \\
\hline Site of airway obstruction (n) & & & 0.505 & 0.613 \\
\hline Trachea & 18 & 62 & & \\
\hline Right and left main bronchus & 25 & 72 & & \\
\hline Pathological type (n) & & & 0.513 & 0.736 \\
\hline Squamous cell carcinoma & 11 & 28 & & \\
\hline Adenocarcinoma & 15 & 37 & & \\
\hline Large cell carcinoma & 12 & 42 & & \\
\hline Small cell carcinoma & 5 & 27 & & \\
\hline \multicolumn{5}{|l|}{ Concomitant disease $(n, \%)$} \\
\hline Hypertension & 13 (30.23\%) & 65 (48.51\%) & 2.100 & 0.036 \\
\hline Anemia & $14(32.56 \%)$ & 36 (26.87\%) & 0.721 & 0.471 \\
\hline TNM staging (n) & & & 0.348 & 0.625 \\
\hline$\|$ & 7 & 21 & & \\
\hline III & 14 & 48 & & \\
\hline IV & 22 & 65 & & \\
\hline
\end{tabular}


2017 to July 2018 in The PLA Navy Anqing Hospital were retrospectively analyzed. According to different treatment method, 43 patients received cryotherapy were included in the control group, while 134 patients received argon plasma coagulation plus cryotherapy were included in the observation group. Propensity score matching was used for further screening, so that the patients in the two groups were in a 1:1 ratio, with 43 cases in each group. After propensity score matching, there were 26 males and 17 females in the control group, aged 36-75 years, with an average age of $46.7 \pm 5.3$ years; in the observation group, there were 23 males and 20 females, aged 32-69 years, with an average age of $47.4 \pm 6.1$ years. Patients were eligible if they had lung cancer at stage II-IV; had poor physical condition and cannot undergo surgical resection; and did not received bronchoscopy intervention for central airway stenosis before. Patients were excluded if they had central airway stenosis caused by non-lung cancer; had immune diseases, organ failure, other malignant tumors, or mental instability; were allergic to treatment drugs, or in pregnancy; had incomplete baseline or outcome data; were uncooperative. This study was approved by the Ethics Committee of The PLA Navy Anqing Hospital, and informed consent was obtained from all the subjects.

\section{Therapeutic method}

Patients in the two groups were all treated with radiotherapy, chemotherapy or targeted therapy (at least one of them). In case of intestinal reaction, antiemetic drugs were prescribed to relieve the symptoms, and gastric mucosa was protected by using gastrointestinal mucosa protectors and proton pump inhibitors. Patients went through enhanced computed tomography, electrocardiogram, blood gas analysis, and strict bronchoscopy for clinical information collection. Before surgery, they were fasted for about $3 \mathrm{~h}$, and given phenobarbital (Tianjin KingYork, China) for sedation, and 2\% lidocaine (Shanghai Zhpharma, China) for spraying anesthesia on their mouth and nose. An appropriate amount of fentanyl (Yichang Humanwell, China) can be injected intravenously according to patient's condition.

Table 2 Baseline data after propensity score matching

\begin{tabular}{|c|c|c|c|c|}
\hline Group & Control group $(n=43)$ & Observation group $(n=43)$ & $t / x^{2}$ & $P$ \\
\hline Sex (male / female) & $26 / 17$ & $23 / 20$ & 0.653 & 0.514 \\
\hline Age (year) & $46.7 \pm 5.3$ & $47.4 \pm 6.1$ & 0.518 & 0.606 \\
\hline Weight (kg) & $57.37 \pm 6.72$ & $59.21 \pm 7.16$ & 1.229 & 0.223 \\
\hline BMI $\left(\mathrm{kg} / \mathrm{m}^{2}\right)$ & $23.28 \pm 3.83$ & $24.42 \pm 4.64$ & 1.423 & 0.218 \\
\hline Nutritional status (n) & & & 0.684 & 0.494 \\
\hline Good & 16 & 13 & & \\
\hline Poor & 27 & 30 & & \\
\hline Airway obstruction (n) & & & 0.453 & 0.651 \\
\hline Mild & 14 & 16 & & \\
\hline Severe & 29 & 27 & & \\
\hline Site of airway obstruction (n) & & & 1.841 & 0.065 \\
\hline Trachea & 18 & 10 & & \\
\hline Right and left main bronchus & 25 & 33 & & \\
\hline Pathological type (n) & & & 0.434 & 0.805 \\
\hline Squamous cell carcinoma & 11 & 10 & & \\
\hline Adenocarcinoma & 15 & 13 & & \\
\hline Large cell carcinoma & 12 & 14 & & \\
\hline Small cell carcinoma & 5 & 6 & & \\
\hline \multicolumn{5}{|l|}{ Concomitant disease $(n, \%)$} \\
\hline Hypertension & $13(30.23)$ & $12(27.91)$ & 0.238 & 0.812 \\
\hline Anemia & $14(32.56)$ & $13(30.23)$ & 0.232 & 0.816 \\
\hline TNM staging (n) & & & 0.632 & 0.729 \\
\hline$\|$ & 7 & 9 & & \\
\hline III & 14 & 11 & & \\
\hline IV & 22 & 23 & & \\
\hline
\end{tabular}


a

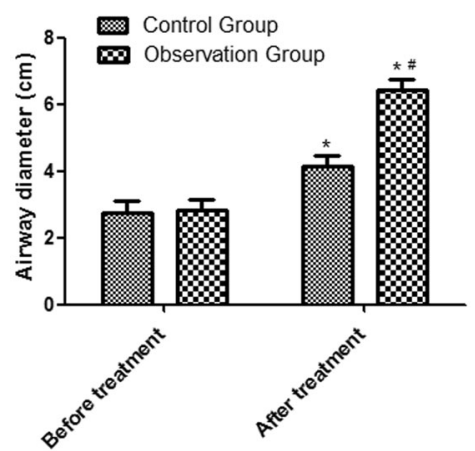

b

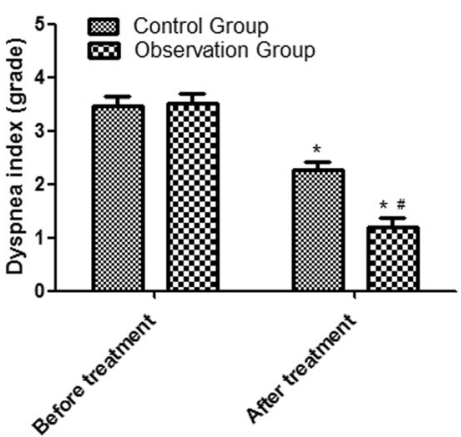

Fig. 1 Comparison of airway diameter and dyspnea index. a Airway diameter. b Dyspnea index. Compared with the control group, ${ }^{\sharp} P<0.05$; compared with before treatment, ${ }^{*} P<0.05$

Then, patients in the control group were treated with cryotherapy. The cryoprobe was acted on the lesion tissues at $-70^{\circ} \mathrm{C}$ to $-45^{\circ} \mathrm{C}$ through the hole of bronchoscopy biopsy, and the frozen lesion was excised after congelation. Then, a stent was placed to keep the airway open. Patients in the observation group were treated with argon plasma coagulation plus cryoablation. The sequence of the two treatments may vary according to patient's condition. The front end of the injection duct of argon was reached out along the bronchoscope until $0.5 \mathrm{~cm}$ away from the tumor tissue. Then, the multi-point coagulation was performed according to the range of lesion tissues. The coagulation time was no more than $3 \mathrm{~s}$, and the eschar on the surface of the lesions was cleared in time.

\section{Outcome measures}

The partial pressure of oxygen $\left(\mathrm{PaO}_{2}\right)$, arterial oxygen saturation $\left(\mathrm{SaO}_{2}\right)$, partial pressure of arterial carbon dioxide $\left(\mathrm{PaCO}_{2}\right)$ were detected one week before and after the treatment, also the occurrences of bleeding, arrhythmia, fever, and hypoxia $\left(\mathrm{PaO}_{2}\right.$ less than 60 $\mathrm{mmHg}$ ) during the postoperative week were recorded. The Karnofsky score in patients was evaluated according to patients' activity ability, self-care ability and disease level. The higher the score, the better the health condition of the subject, and 100 points indicated a healthy condition; 0 point indicated a critical state. The dyspnea index in patients was also measured, and grade 0 referred to eupnea; grade 1 referred to shortness of breath during walking; grade 2 referred to shortness of breath during fast walking; grade 3 referred unable to walk because of shortness of breath; grade 4 referred extremely easy occurrence of shortness of breath [6].

\section{Evaluation criteria}

The efficacy was evaluated one week after treatment, and the criteria of effect on airway stenosis were as follows: completely effective referred to complete clear of airway obstruction and normal respiratory function; partially effective referred to over $50 \%$ reduction of airway obstruction and improved respiratory function; mild effective referred to $20-50 \%$ reduction of airway obstruction and partially improved respiratory function; ineffective referred to no improvement in airway obstruction [8].

The follow up was carried out through outpatient or telephone until May 31, 2019 to record the clinical symptoms and survival.

\section{Statistical analyses}

Data in this study were processed with the use of SPSS.21.0. To reduce selection bias, propensity score matching was used for further subject screening, so

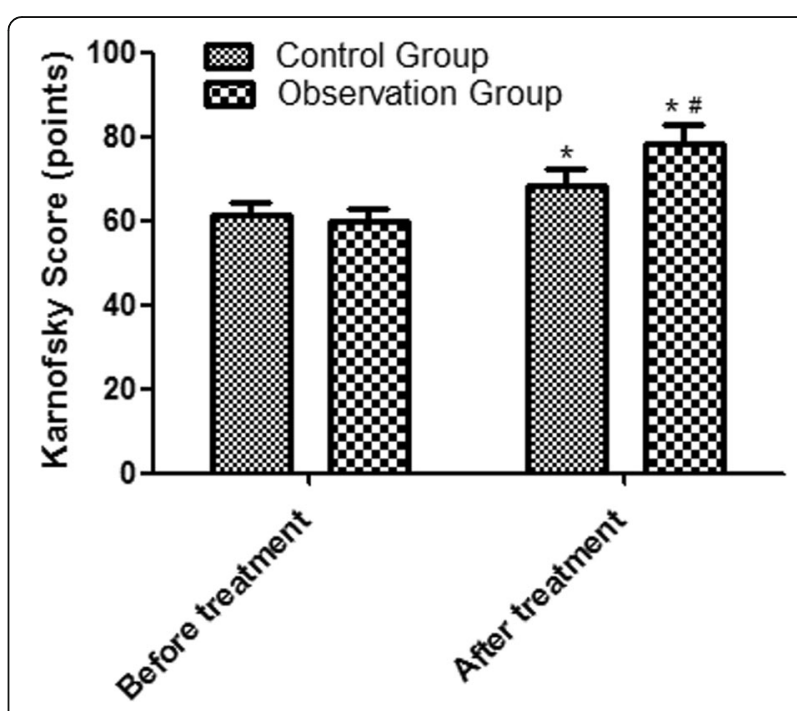

Fig. 2 Comparison of Karnofsky score. Compared with the control group, ${ }^{\#} P<0.05$; compared with before treatment, ${ }^{*} P<0.05$ 
Table 3 Comparison of arterial blood-gas parameters

\begin{tabular}{lllll}
\hline Group & Time & $\mathrm{PaO}_{2}(\mathrm{mmHg})$ & $\mathrm{PaCO}_{2}(\mathrm{mmHg})$ & $\mathrm{SaO}(\%)$ \\
\hline Control group & Before treatment & $54.36 \pm 4.63$ & $43.46 \pm 3.37$ & $82.46 \pm 5.73$ \\
& After treatment & $64.23 \pm 4.62^{*}$ & $39.24 \pm 3.12^{*}$ & $91.36 \pm 8.64^{*}$ \\
Observation group & Before treatment & $56.37 \pm 5.13$ & $44.51 \pm 4.42$ & $83.72 \pm 5.48$ \\
& After treatment & $73.29 \pm 6.27^{* \#}$ & $34.26 \pm 3.17^{* \#}$ & $97.34 \pm 9.24^{* \#}$ \\
\hline
\end{tabular}

Compared with the control group, ${ }^{\#} P<0.05$; compared with before treatment, ${ }^{*} P<0.05$

that the patients in the two groups were in a $1: 1$ ratio. The measurement data were expressed as mean \pm standard deviation, and processed using paired $t$ test (between before and after intervention within group) and independent sample $t$ test (between groups at the same time point). The count data were expressed as rate, processed using $X^{2}$ test. Ranked data were processed using Wilcoxon-Mann-Whitney test. $P<0.05$ was considered statistically significant.

\section{Results}

\section{Analysis of baseline data}

At baseline, there were statistically significant differences in BMI, nutritional status, airway obstruction and concomitant hypertension between the observation group and the control group (all $P<0.05$ ), while there was no significant difference in gender, age, site of airway obstruction, pathological type, concomitant anemia, or tumor-node-metastasis (TNM) stage between the two groups (all $P>0.05$ ). See Table 1 . After propensity score matching, the differences in gender, age, body mass index, nutritional status, airway obstruction, site of airway obstruction, pathological type, concomitant disease, and TNM staging were all not significant between the two groups (all $P>0.05$ ). See Table 2 .

\section{Comparison of airway diameter and dyspnea index}

Before treatment, the airway diameters of the control group and the observation group were $2.68 \pm 0.42 \mathrm{~cm}$, and $2.68 \pm 0.47 \mathrm{~cm}$, respectively, without statistical difference $(P>0.05)$. The post-treatment airway diameters of the control group and the observation group were $4.29 \pm 0.64 \mathrm{~cm}$ and $6.34 \pm 0.86 \mathrm{~cm}$ respectively, which were both significantly larger than those of before treatment, and the post-treatment diameter of the observation group was larger than that of the control group (all
$P<0.05)$. Before treatment, the dyspnea index of the control group and the observation group were grade $3.41 \pm 0.39$ and grade $3.47 \pm 0.36$, respectively, without statistical difference $(P>0.05)$. The post-treatment dyspnea index of the control group and the observation group were grade $2.46 \pm 0.36$ and grade $1.29 \pm 0.27$ respectively, which were significantly lower than those of before treatment, and the post-treatment index of the observation group was lower than that of the control group (all $P<0.05$ ). See Fig. 1 .

\section{Comparison of Karnofsky score}

The post-treatment Karnofsky scores of the control group and the observation group were $65.28 \pm 7.64$ points and $76.29 \pm 8.37$ points, respectively, which were significantly higher than those of before treatment, and the post-treatment score of the observation group was higher than that of the control group (all $P<0.05$ ). See Fig. 2.

\section{Arterial blood-gas analysis}

In the observation group, the post-treatment $\mathrm{PaO}_{2}$ was $73.29 \pm 6.27 \mathrm{mmHg}$ and $\mathrm{SaO}_{2}$ was $97.34 \pm 9.24 \%$, which were significantly higher than those of the control group, and $\mathrm{PaCO}_{2}$ was $34.26 \pm 3.17 \mathrm{mmHg}$, which was significantly lower than that of the control group (all $P<0.05$ ). In both groups, the levels of post-treatment $\mathrm{PaO}_{2}$ and $\mathrm{SaO}_{2}$ were significantly higher than those of before treatment, and the levels of post-treatment $\mathrm{PaCO}_{2}$ were significantly lower than those of before treatment (all $P<0.05$ ). See Table 3.

\section{Comparison of effective rate}

The rate of completely effective in the observation group was $37.21 \%$, and the rate of mildly effective was $11.63 \%$, which were significantly different from those in the

Table 4 Comparison of effective rate $(n, \%)$

\begin{tabular}{lllll}
\hline Group & Completely effective & Partially effective & Mildly effective & Ineffective \\
\hline Control group $(n=43)$ & $7(16.28)$ & $17(39.53)$ & $15(34.88)$ & $4(9.31)$ \\
Observation group $(n=43)$ & $16(37.21)$ & $20(46.51)$ & $5(11.63)$ & $2(4.65)$ \\
$X^{2}$ & 2.193 & 0.653 & 2.553 & 0.847 \\
$P$ & 0.028 & 0.514 & 0.011 & 0.392 \\
\hline
\end{tabular}


control group (both $P<0.05$ ). The partially effective and ineffective rates of the observation group were 46.51 and $4.65 \%$, respectively, and there was no significant difference in these two rates as compared with the control group (both $P>0.05$ ). See Table 4 .

\section{Comparison of post-treatment adverse reactions}

In the observation group, the incidence of bleeding was $11.63 \%$; of arrhythmia was $13.95 \%$, and of fever was $18.60 \%$, which were significantly lower than those in the control group (all $P<0.05$ ). There were 7 patients with $\mathrm{PaO}_{2}$ less than $60 \mathrm{mmHg}$ in the observation group, with an hypoxia incidence of $16.28 \%$, which was not significantly different from that in the control group $(P>0.05)$. See Table 5.

\section{Comparison of survival rates}

Patients in both groups were followed up to May 31, 2019, with a successful follow-up rate of $100 \%$. In the control group, 21 cases died and 22 cases survived, with a survival rate of $51.16 \%$. In the observation group, 12 cases died and 31 cases survived, with a survival rate of $72.09 \%$. The survival rate in the observation group was significantly higher than that in the control group $(P<0.05)$.

\section{Discussion}

Most patients with lung cancer are diagnosed at the advanced stage with poor health condition, which is a bad timing for surgery [10]. Due to the particularity of lung cancer lesions, excessive growth of tumor tissues can induce airway stenosis and obstruction in patients, leading to dyspnea or shock [11]. Chemoradiotherapy can inhibit the growth of tumor tissues, but cannot timely relieve the dyspnea caused by central airway obstruction, so it is not suitable for critical patients [12, 13]. Therefore, exploring a reasonable plan for the treatment of central airway obstruction is of important clinical significance.

This study found that the post-treatment airway diameter, Karnofsky score, and dyspnea index were better in the observation group than those in the control group, suggesting that the treatment for the observation group was better for the patients' respiratory function and health condition. We also found that the post-treatment levels of $\mathrm{PaO}_{2}$ and $\mathrm{SaO}_{2}$ in the observation group were higher than those in the control group, and the $\mathrm{PaCO}_{2}$ was lower in the observation group than that in the control group, suggesting that argon plasma coagulation combined with cryotherapy can improve the hypoxic state of patients. Cryotherapy uses liquid nitrogen or carbon dioxide to damage the lesion tissues, and induces necrosis of the lesion through low temperature, which is not easy to cause complications such as bronchial perforation. However, the cryotherapy has limited freezing depth to lesion tissues, so it's not promising for clearing large tumor tissues, and relieving airway stenosis [14, 15]. Argon plasma coagulation can damage the lesion tissues from various angles, which effectively clears the tumor tissues [16]. In the observation group, the completely effective rate and mildly effective rate were 37.21 and $11.63 \%$, respectively, which were significantly different from those of the control group, while the partially effective rate and ineffective rate were 46.51 and $4.65 \%$, respectively, which were not significantly different from the control group, suggesting that the argon plasma coagulation combined with cryotherapy had better treatment effect, which is consistent with previous study [17].

Adverse reactions including bleeding, arrhythmia, fever and hypoxia occurred in some patients in both groups, but the incidences of bleeding, fever and arrhythmia in the observation group were significantly lower than those in the control group. Argon plasma coagulation can easily increase the temperature of patient's airway and cause damage to the airway mucosa during operation, leading to airway burns and even perforation, and sometimes hypoxemia. Therefore, it is necessary to pay special attention to the coagulation time during operation $[18,19]$. Due to the abundant blood vessels in the airway tumor tissue, the blood coagulation effect of cryotherapy on the bleeding tissue is not favorable, and patients are prone to bleeding [20]. Cryotherapy and excision after argon plasma coagulation can better remove the necrotic tissues, and the hemostatic effect of argon is beneficial to alleviating the tissue damage during cryotherapy, which further reduces airway damage and reduce the incidence of complications [21, 22]. In this study, the mortality of the observation group was lower than that of the control group, probably because argon plasma coagulation combined with cryotherapy showed better efficacy for central airway stenosis, and resulted in lower incidence of complications, thereby improving the prognosis in patients. However, the sample size included in this study was insufficient, and the follow-up period

Table 5 Comparison of adverse reactions

\begin{tabular}{lllll}
\hline Group & Hypoxia & Bleeding & Arrhythmia & Fever \\
\hline Control group $(n=43)$ & $6(13.95)$ & $13(30.23)$ & $14(32.56)$ & $17(39.53)$ \\
Observation group $(n=43)$ & $7(16.28)$ & $5(11.63)$ & $6(13.95)$ & $8(18.60)$ \\
$X^{2}$ & 0.301 & 2.121 & 2.042 & 2.137 \\
$P$ & 0.763 & 0.034 & 0.041 & 0.033 \\
\hline
\end{tabular}


we carried out should be prolonged for further analysis of the postoperative outcome, so further studies with improved protocol are needed.

\section{Conclusions}

Argon plasma coagulation combined with cryotherapy can significantly alleviate the central airway stenosis caused by lung cancer, reduce the incidence of adverse reactions, and improve the prognosis in patients.

\section{Abbreviations}

$\mathrm{PaCO}_{2}$ : partial pressure of arterial carbon dioxide; $\mathrm{PaO}_{2}$ : partial pressure of oxygen; $\mathrm{SaO}_{2}$ : arterial oxygen saturation; TNM: tumor-node-metastasis

\section{Acknowledgements}

Not applicable.

\section{Authors' contributions}

ZW designed and performed the research, as well as wrote the paper; WW collected and analyzed the data; GW designed and supervised the experiment process. All authors read and approved the final manuscript.

\section{Funding}

Not applicable.

\section{Availability of data and materials}

The datasets used and/or analysed during the current study are available from the corresponding author on reasonable request.

\section{Ethics approval and consent to participate}

This study was approved by the Ethics Committee of The PLA Navy Anqing Hospital, and informed consent was obtained from all the subjects.

\section{Consent for publication}

Not applicable.

\section{Competing interests}

The authors declare that they have no competing interests.

Received: 10 May 2019 Accepted: 20 August 2019

Published online: 28 August 2019

\section{References}

1. Jalilie A, Carvajal JC, Aparicio R, Meneses M. Electrocautery and bronchoscopy as a first step for the management of central airway obstruction and associated hemoptysis. Rev Med Chil. 2016;144:1417-23.

2. Barnes D, Gutierrez Chacoff J, Benegas M, Perea RJ, de Caralt TM, Ramirez J, et al. Central airway pathology: clinic features, $C T$ findings with pathologic and virtual endoscopy correlation. Insights Imaging. 2017;8:255-70.

3. Matsumoto K, Yamasaki N, Tsuchiya T, Miyazaki T, Kamohara R, Hatachi G, et al. Double stenting with silicone and metallic stents for malignant airway stenosis. Surg Today. 2017:47:1027-35.

4. Lee J, Park YS, Yang SC. The endoscopic cryotherapy of lung and bronchial tumors: a systematic review -can we expect a new era of cryotherapy in lung cancer? Korean J Intern Med. 2011;26(2):132-4.

5. Verma A, Phua CK, Wu QM, Sim WY, Rui AW, Goh SK, et al. Our clinical experience of self-expanding metal stent for malignant central airway obstruction. J Clin Med Res. 2017;9:58-63.

6. Fruchter $\mathrm{O}$, Abed El Raouf $\mathrm{B}$, Rosengarten $\mathrm{D}$, Kramer MR. Long-term outcome of short metallic stents for lobar airway stenosis. J Bronchology Interv Pulmonol. 2017;24:211-5.

7. Karush JM, Seder CW, Raman A, Chmielewski GW, Liptay MJ, Warren WH, et al. Durability of silicone airway stents in the Management of Benign Central Airway Obstruction. Lung. 2017;195:601-6.

8. Pandit A, Gupta N, Kumar V, Bharati SJ, Garg R, Madan K, et al. Effect of palliative Bronchoscopic interventions on symptom burden in patients with central airway narrowing: a retrospective review. Indian J Palliat Care. 2019; 25(2):250-3.
9. Gil D, Ortiz RM, Sanchez C, Rosell A. Objective endoscopic measurements of central airway stenosis: a pilot study. Respiration. 2018:95:63-9.

10. Wang H, Pan Z, Jiang Y, Shao K, Hu L, Feng G. Correlation between nasopharyngoscopy and magnetic resonance imaging (MRI) in locating the upper airway obstruction plane in male obstructive sleep apnea hypopnea syndrome (OSAHS) patients. Sleep and Biological Rhythms. 2017;15:269-76.

11. Kızlgöz D, Aktaş Z, Yılmaz A, Öztürk A, Seğmen F. Comparison of two new techniques for the management of malignant central airway obstruction: argon plasma coagulation with mechanical tumor resection versus cryorecanalization. Surg Endosc. 2018;32(4):1879-84.

12. Saka H, Kada A. An open-label, single-arm study of $\mathrm{CRYO} 2$ for tissue removal at the site of central airway obstruction or stenosis: study protocol. Nagoya J Med Sci. 2018:80:411-5.

13. Wong SKH. Endoscopic full-thickness transoral outlet reduction with endoscopic submucosal dissection or argon plasma coagulation: does it make a difference? Endoscopy. 2019;51(7):617-8.

14. Nishine $H$, Muraoka H, Inoue T, Miyazawa T, Mineshita M. Pulmonary perfusion using Intrabronchial capnography in pulmonary artery stenosis. Respiration. 2018;95:465-8.

15. Janke KJ, Abbas AE, Ambur V, Yu D. The application of liquid nitrogen spray cryotherapy in treatment of bronchial stenosis. Innovations (Phila). 2016; 11(5):349-54.

16. Ni C, Yu H, Han X, Meng C, Zhang Y. Clinical analysis of bronchoscopic cryotherapy in 156 pediatric patients. Pediatr Int. 2017;59(1):62-7.

17. Lee BR, Oh IJ, Lee HS, Ban HJ, Kim KS, Kim Yl, et al. Usefulness of rigid Bronchoscopic intervention using argon plasma coagulation for central airway tumors. Clin Exp Otorhinolaryngol. 2015;8(4):396-401.

18. DiBardino DM, Lanfranco AR, Haas AR. Bronchoscopic cryotherapy. Clinical applications of the Cryoprobe, Cryospray, and Cryoadhesion. Ann Am Thorac Soc. 2016;13(8):1405-15.

19. Robinson M, Smiley M, Kotha K, Udoji T. Plastic bronchitis treated with topical tissue-type plasminogen activator and cryotherapy. Clin Pediatr (Phila). 2016:55(12):1171-5.

20. Wong JL, Tie ST, Lee J, Kannan SK, Rashid Ali MR, Ibrahim A, Abdul Rahman JA. A case of recurrent respiratory papillomatosis successfully removed via endoscopic argon plasma coagulation (APC) with no evidence of recurrence. Med J Malaysia. 2014:69(4):195-6.

21. Shu L, Hu Y, Wei R. Argon plasma coagulation combined with a flexible electronic bronchoscope for treating foreign body granulation tissues in Children's deep bronchi: nine case reports. J Laparoendosc Adv Surg Tech A. 2016;26(12):1039-40

22. Pedoto A, Desiderio DP, Amar D, Downey RJ. Hemodynamic instability following airway spray cryotherapy. Anesth Analg. 2016;123(5):1302-6.

\section{Publisher's Note}

Springer Nature remains neutral with regard to jurisdictional claims in published maps and institutional affiliations.

Ready to submit your research? Choose BMC and benefit from:

- fast, convenient online submission

- thorough peer review by experienced researchers in your field

- rapid publication on acceptance

- support for research data, including large and complex data types

- gold Open Access which fosters wider collaboration and increased citations

- maximum visibility for your research: over $100 \mathrm{M}$ website views per year

At BMC, research is always in progress.

Learn more biomedcentral.com/submission 